JGM

6,2

\title{
Editorial
}

126

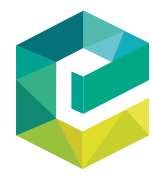

Journal of Global Mobility Vol. 6 No. 2, 2018 pp. $126-128$

C) Emerald Publishing Limited 2049-8799 DOI 10.1108/JGM-06-2018-067

\section{Are highly ranked academic journals better?}

Sometimes, I see articles on global mobility and expatriate management published in other outlets than the Journal of Global Mobility (JGM). And I cannot help but think to myself: would this have been accepted for publication in JGM? Such thoughts may even go through my mind when I read articles in highly ranked academic journals, especially if they are of a more general management or international business character. Although the non-specialist aspects of articles in such journals tend to be impeccable, like methodology and statistical analyses, sometimes I (and perhaps others) wonder what the contribution really is to the literature on global mobility and expatriate management. This is the unassailable strength of a specialist academic research journal like JGM; we have all the resources at our fingertips that we need to contribute significantly to our literature. JGM is the only academic journal to consistently and exclusively focus on global mobility and expatriate management, and the journal is managed by experts, for experts. The Editorial Advisory Board of JGM reads as a who's who in our area and the editorial team, reviewers and authors are all specialists. The academic community has also recognized this competitive advantage. Despite being only in its sixth year, JGM went straight into the no. 2 level of the Chartered Association for Business Schools (CABS, UK) Academic Journal Guide 2018. Even before this, JGM was indexed in Scopus (CiteScore 2016: 1.65) and ESCI. The journal is also ranked by the Australian ABDC List as a B journal and ranked by the Nordic countries and Brazil.

To highlight topics of special interest and to stimulate future research, $J G M$ also publishes special issues. The two most recent ones focused on important but often neglected areas. The first was, Beyond Corporate Expatriation: Examining Neglected Non-Corporate Communities, edited by Yvonne McNulty, Charles Vance and Kelly Fisher. The second special issue was: Dangerous Moves and Risky International Assignments, edited by Luisa Helena Pinto, Benjamin Bader and Tassilo Schuster. Two special issues are scheduled for next year: The Dark Side of Global Mobility (paper submission deadline September 15, 2018), edited by Benjamin Bader, Tassilo Schuster, Anna Katharina Bader and Margaret Shaffer; and Low Status Expatriates (paper submission deadline March 1, 2019) edited by Chris Brewster, Washika Haak-Saheem and Jakob Lauring.

$J G M$ now has a distinct presence on social media with a JGM LinkedIn Group, a JGM Facebook Group (please contact Yvonne ymcnulty@expatresearch.com if you want to join) and a Twitter account, @JanSelmer_JGM. They all feature JGM-associated content.

At JGM, we welcome all kinds of rigorous research methods, but we also publish thorough theoretical developments and focused literature reviews. Besides that, we would like to feature research at various levels of analysis - individual, team, organizational, or even regional or national. We are interested in research from a variety of academic domains, as well as cross-disciplinary studies.

As opposed to many other academic research journals, JGM welcomes replication studies that build on and provide useful extensions of prior findings. We believe that, as important that it is for science to break new ground, previous discoveries must be examined again to reaffirm or disconfirm their existence. Without repeating much of the ongoing academic debate on the subject, replication studies can be of various forms, where previous results are investigated with same or different methodologies and settings as well as providing extensions of primary research. 
In this issue

Editorial

The first article in this issue is authored by Jil Weisheit and deals with the international relocation mobility readiness (IRMR) of employees. Based on 88 journal articles, a content analysis revealed that studies seldom provide a conceptualization of IRMR since there tends to be a misfit between the studies' explicit conceptualization and the actual measurement of IRMR. Actually, most scales measure willingness and not readiness. Future research is recommended to conceptualize IRMR as a dynamic multidimensional construct, covering the different phases of an individual's decision to relocate internationally. The succeeding article, written by Stine Waibel, Tim Aevermann and Heiko Rueger, examines the health-related well-being of public sector expatriates, and especially their family situation. Sampling the entire staff of the German Foreign Service (GFS), 1,390 members responded to questions about partnership status, childlessness and experiences of partnership break-ups. Results showed that females are overrepresented among GFS employees who experience partnership instability as well as among single and childless employees. This is a novel contribution to the literature since the system-wide rotational staff mobility of public service institutions has received scarce attention. Hanan Saber Almazrouei, Robert Zacca, Joel Evans and Mumin Dayan have authored the third article exploring whether an expatriate managers' favorability toward accepting a foreign assignment affects the way they respond to subsequent treatment in the workplace, especially in terms of organizational justice. Results, based on data collected from 175 expatriate managers located in the United Arab Emirates, showed that expatriate managers who express a higher degree of favorability toward accepting a foreign assignment appear less reactive to changes in organizational fairness and vice versa. The latter expatriate managers may harbor deep questions about whether they want to be in this new job capacity, and may therefore be more sensitive to how they are treated while the others may have already decided they want to be in the new capacity, and so may be more robust to workplace treatment. This is a novel investigation of the effects of expatriate pre-departure opinion on job satisfaction and commitment within the context of organizational justice. The fourth article examines the influences of expatriate community relationship building behaviors on community embeddedness as well as community embeddedness on expatriate retention cognitions and is authored by Dilek Yunlu, Hong Ren, Katherine Mohler Fodchuk and Margaret Shaffer. Based on survey data from 127 expatriates in the USA, results indicated that community relationship building behaviors positively influence expatriate community embeddedness, and the latter is associated with stronger retention cognitions. Additionally, community embeddedness is particularly important for individuals who have lower levels of organizational identification. This study integrates the unique view of personal resources associated with different social contexts in expatriate studies. The fifth contribution to this issue is written by Shih Yung Chou. This article develops a conceptual model describing how immigrant employees' organizational citizenship behaviors (OCBs) are influenced by their immigrant status. The study explores the mediating role of perceived job mobility and the moderating role of organizational tenure in the relationship between immigrant status and OCBs. Besides providing a novel theoretical base that could guide future research on immigrant employees' OCBs in organizations, this paper also offers practical recommendations that may help maximize the effectiveness of immigrant employee's OCBs. The sixth and last article in this issue deals with how organizations can increase employees' willingness to relocate internationally, with Chun-Hsiao Wang as the author. Based on a sample of 229 employees from a large and global-minded Taiwanese bank, results showed that when employees perceived international assignment experience to be valuable to their career and valued by their organization, they reported a higher level of willingness to relocate internationally. Consequently, organizations may want to communicate clearly that they value employees' international assignment experience before, during and after their assignment. 
JGM

6,2
Confirming the competitive advantage of $J G M$, through the most recent success of its editorial team, by achieving the CABS no. 2 rating, we are confidently looking forward to the outcome of our application for SSCI status for JGM to be announced later this year. With that accomplished, JGM will finally be on a level playing field with its competitors but will still retain its special power as an academic research journal managed by experts, for experts. The JGM Editorial Advisory Board, the editorial team and the best specialist reviewers all contribute to establishing JGM as the leading outlet for academic research on global mobility and expatriate management.

Jan Selmer 